\title{
AN ANALYSIS OF COMMUNICATION TYPES OF DEAF STUDENTS WITH ENVIRONMENT
}

\author{
Cipta Rizqi Rahmah ${ }^{1)}$, Abdul Kholiq ${ }^{2)}$ \\ Universitas Islam Lamongan \\ ciptarizqi08@gmail.com ${ }^{1)}$, abdulkholiq@unisla.ac.id ${ }^{2}$
}

\begin{abstract}
The research aimed to analysis (1) the deaf student communicate with the deaf student; (2) with other disability; and (3) with normal people. This research used a qualitative approach. The sources of data are focusing on the communication types of deaf students by three deaf people SMALB Banjarmendalan Lamongan academic year 2016/2017. Data Collection Techniques are interview; observation; and documentation. Research Instruments in this study are a notebook to write about the interview; checklist paper; and field note. Analyzing technique in this study are organizing, coding and reducing, interpreting and representing. The result of this study are Deaf children's communication with deaf children is more dominant using nonverbal rather than verbal. Use of continuous verbal communication such as Kinect (facial expression, eye contact, sign language), haptics, paralanguage, and proxemict. Deaf children communicate with other disability (down syndrome) is Deaf children's communication with dominant down syndrome children using nonverbal communication types. The use of intense verbal communication such as kinestict (facial expressions, eye contact, sign language) and haptics are two very important aspects of their communication. Deaf children's communication with normal people uses a combination of verbal (oral and writing) and nonverbal (kinect, haptic, and proxemic). Teachers will use a clear combination of sign language and oral. While researchers use oral, written and sign language to make it easier for deaf students to understand the conversation.
\end{abstract}

Keywords: Communication Types, Deaf Student, Disability

\section{INTRODUCTION}

Communication is the process of delivering thoughts or feelings by a person (communicator) to others (communicant). Thought can include information, opinion, and others that emerge from his mind. Communication is a series of processes or events that occur are related to one another, the communication process involves many elements (McQual in Burhan, 2006). Factors or elements that referred to among others may include participants, messages (including the form, content, and how to express). Communication can be done in a way that is simple to complex. Communication is not limited to words or speech, but any form of interaction, a smile, nodding of the head, gesture, facial expression, behavior, and feelings.

Communication is divided into two types, verbal communication, and nonverbal communication. Verbal communication is a form of communication between the communicator with the communicant, either in written or orally. Oral communication is a spoken interaction between two or more people. This interaction is more complex than it looks. Oral communication consists of many complementary aspects and if one of these aspects is incomplete it will have an impact on the success or failure of the interaction. Not everyone is an effective communicant. Merely communication is more than an exchange of words between 
parties. Meanwhile, non-verbal communication also occupies an important role. Much verbal communication is not effective simply because the communicator not use non-verbal communication with both at the same time. Examples: touch and gestures.

The language of communication is sent and message receive activity both orally and in writing, the language used to speak or relate to one another. At the moment we use language as a communication means, we already have a specific purpose. We wanted to convey the idea that can be accepted by others. We want to make others understand what we deliver. Communication will proceed smoothly if the interlocutors are able to understand what was being said.

Communication is the process of sending and receiving messages or information between two or more individuals effectively so that it can be understood easily. According to Julia (2006, p.5), Communication is a systemic process in which people interact with and through symbols to create and interpret meaning. The term communication in English called communication, which comes from the word communication that has the same meaning or the same that has the meaning of mutual understanding. Communication can also mean sending and receiving messages or news from two or more people so that the intended message can be understood. Communication is divided into two types, namely verbal communication and nonverbal communication.

Verbal communication is a conversation activity or delivery of information performed by one person to another, either orally or in writing. Verbal communication can be done using the media, for example, someone who speaks by phone. While verbal communication through writing is done by indirectly between communicator with communicant. The process of delivering information conducted by using letters, paintings, drawings, graphics, and others.

Speaking is verbal communication. While writing is verbal-non vocal communication. Examples of verbal communication-vocal presentations in meetings and examples of verbal-non vocal communication are business correspondence. Listening also verbal communication. listening means simply picking up the sound vibration while listening is taking the meaning of what is heard. Listening involves the four elements of listening, caring, understanding and remembering. Reading is a way of getting information from something written.

Non-verbal communication is a process of delivering messages to others by not using words. All the movements of the human body have a meaning and no incidental movement. The example of nonverbal communication is the use of gestures, body language, facial expressions, and eye contact, symbols, and speech-ways such as intonation, emphasis, emotion and speaking style.

According to Julia (2009, p.138), Kinesics is body position and body motions, including those of the face. There are several types of kinesics, 1) facial expression. Facial expressions are part of nonverbal communication. Even before we hear what they say; 2) the eyes contact. Our eyes communicate some of the most important and complex messages about how we feel (Julia, 2009, p. 138). Eyes contact an important role in nonverbal communication and such things as looking, staring and blinking are important 
nonverbal behaviors. When people encounter people or things that they like, the rate of blinking increases and pupils dilate. Looking at another person can indicate a range of emotions including hostility, interest, and attraction; 3) body posture and gesture. According to Julia (2009, p. 138) Body postures and gestures may signal whether we are open to interaction and how we feel about others. Deliberate movements and signals are an important way to communicate meaning without words. Common gestures include waving, pointing, and using fingers to indicate numeric amounts.

According to Whitman in Julia (2009, p. 139). Haptics is physical touch, touch is the first of our senses to develop, and many communication scholars believe that touching and being touched are essential to a healthy life. Haptics is nonverbal communication. Touches can include: shaking hands, holding hands, kissing, touching back, stroking, punching, and others. Each of these forms of communication conveys a message about the purpose or feelings of the toucher. Touch can also cause a feeling to the touch receiver, both positive and negative.

According to Julia (2009, p. 146), Paralanguage is vocal communication that does not involve words. It includes sounds, such as murmurs and gasps, and vocal qualities, such as volume, rhythm, pitch, and inflection. Paralanguage is one of the nonverbal element in a speech. The science that studies this is called paralinguistic. Examples are a tone of speech, tone of voice, loud or weak voice, speaking speed, sound quality, intonation, and others. In addition, the use of filler sounds such as "mm", "e", "o", "um", while speaking is also classified as vocalic, and in good communication, such things should be avoided. Paralanguage refers to vocal communication that is separate from actual language. This includes factors such as tone of voice, loudness, inflection, and pitch.

Consider the powerful effect that tone of voice can have on the meaning of a sentence. When said in a strong tone of voice, listeners might interpret approval and enthusiasm. The same words said in a hesitant tone of voice might convey disapproval and a lack of interest. Consider all the different ways simply changing your tone of voice might change the meaning of a sentence. A friend might ask you how you are doing, and you might respond with the standard "I'm fine," but how you actually say those words might reveal a tremendous amount of how you are really feeling. A cold tone of voice might suggest that you are actually not fine, but you don't wish to discuss it. A bright, happy tone of voice will reveal that you are actually doing quite well. A somber, downcast tone would indicate that you are the opposite of fine and that perhaps your friend should inquire further.

\section{Proxemics}

Proxemic is space and how we use it. Every culture has norms for using space and for how close people should be to one another (Afifi and Burgoon in Julia, 2000, p. 142). People often refer to their need for "personal space," which is also an important type of nonverbal communication. The amount of distance we need and the amount of space we perceive as belonging to us is influenced by a number of factors including social norms, cultural expectations, situational factors, personality characteristics, and level of familiarity. 


\section{Artifacts}

Objects and images are also tools that can be used to communicate nonverbally. On an online forum, for example, you might select an avatar to represent your identity online and to communicate information about who you are and the things you like. People often spend a great deal of time developing a particular image and surrounding themselves with objects designed to convey information about the things that are important to them. Uniforms, for example, can be used to transmit a tremendous amount of information about a person. A soldier will don fatigues, a police offers will wear a uniform, and a doctor will wear a white lab coat. At a mere glance, these outfits tell people what a person does for a living

\section{Chronemics}

Chronemics is how we perceive and use the time to define identities and interaction (Julia, 2009, p. 145). Chronemic is a field that uses the use of time in nonverbal communication. The use of time in nonverbal communication includes the duration that can be suitable for an activity, the number of activities required in a certain period of time, and the timeliness (punctuality).

\section{Silence}

A final type of nonverbal behavior is silence. Silence is an indispensable element in communication. Without silence, rich words of meaning cannot be born. Silence can mean positive and negative and can be interpreted anything. For example, when someone we talk to but he is silent. Silence can mean, shy, fear or refuse.

However, everyone is not always in normal conditions. Category normal means not encounter an obstacle or any disruptions mental condition, physical and cognition, or better known by the name of disability. Disability is defined as the inability to perform an activity or activities as a normal person. While the defect is an abnormality or damage to limbs and so forth that cause the condition becomes deficient or abnormal (Kementrian Kesehatan RI, 2014:05). Various disability blind, mute, deaf, down syndrome, Physical Disabilities, Self-Control Defects.

Disability is a condition where a malfunction of one or several parts of his body, so that the person loses the ability to do things as a normal person. According to Susenas in Kementerian Kesehatan RI (2014, p.6), disability is the inability to perform an activity or activities as a normal person who caused the condition of impairment (loss/ inability) associated with age and society. Persons with disabilities include those who have physical limitations, mental, intellectual or sensory impairments in the long term and when faced with various obstacles, it may hinder their full participation and effectiveness in society on an equal basis with others.

Problems or cases faced by people with a disability there are various kinds. Various Kinds/Types of disability or disorder in humans: Blind; Mute; Physical Disabilities; Mental Backwardness; SelfControl Defects; Disabled Combinations; Deaf. A deaf people a person who does not have the ability to hear as normal people in general. People who have a severe hearing disability who do not can still use a hearing aid so they can come back to hear properly.

According to Soemantri (2006: 93), deaf is a condition of losing hearing that leads to someone cannot catch a stimulation, especially through the of hearing. In general, children with hearing 
impairment are having problems with the ability to hear and convey the spoken language so that deaf children should be encouraged to develop sign language. Communicating with deaf children not only use hearing aids or sign language but also should encourage children to talk although their speech is limited. Children who suffer from hearing impairment since childhood could not speak, referring to the children who do not understand that all things in this world have a name meaning, for example, glasses, chairs, and other objects.

Deaf children can be said to be children who have limitations in receiving language but use nonverbal communication (Moores, 1974). Definitions of deaf children have often mentioned by experts who all it basically contains the same understanding. According to Dwidjosumarto in Soemantri (2006, p.93) suggested that a person who is not or less able to hear the voice said to be deaf. Deaf divided into two categories namely, the deaf and hearing less. Deaf their senses of hearing damage in its early stages so that the weight loss does not work anymore. While less heard their senses of hearing is damaged but can still function to hear, either with or without the use of hearing aids.

According to Soemantri (2006, p.93) concludes that a deaf child is a child who experienced a lack or loss of hearing ability due to damage or malfunction in part or all of the hearing instrument so that it faces obstacles in language development. So a deaf child is a child who cannot hear and know the meaning of an object.

The verbal language of deaf children can be developed in accordance with their conditions if they are given the maximum opportunity to develop skills that allow them to communicate as much as possible. Therefore, special education is needed to handle deaf students. Such education can be obtained at extraordinary schools or in Indonesian called as Sekolah Luar Biasa (SLB).

In order to seek the communication type of deaf student with the environment, the current research was designed to investigate the following questions: 1) How the deaf student communicate with the deaf student?; 2) How the deaf student communicate with other disability?; 3) How the deaf student communicate with normal people?

\section{RESEARCH METHOD}

This research used a qualitative descriptive (Afifudin \& Beni, 2009). The place of this study at SMALB Banjarmendalan Lamongan. It is where some children who have needs and disabilities that make them harder to learn than other children at the same age. SMALB Banjarmendalan Lamongan is the same with Senior High School for normal people, but they have different competence standard for the student. There is a particular class for deaf including the participant or object in this research. The researcher took this class due to relating to this research. The sources of data are focusing on the communication types of deaf students by three deaf people SMALB Banjarmendalan Lamongan academic year 2016/2017.

The first subject is Rifqi (S1), he was born and suffered deaf. He classified as a low level. At school, he includes a clever and competent student. When he does not understand the lesson he will continue to ask until he understands but when communicating with a new person he to be quiet. The second subject (S2) is Firda, she 
was born and suffered deaf. She classified as a medium level. At school, she includes a very active and easy to communicate student. She has a hobby of making up and drawing. The last subject (S1) he is Tio. $\mathrm{He}$ was born and suffered deaf. $\mathrm{He}$ classified as a high level. Ti has a closed person, he is difficult to communicate even though it with his friend. He often plays handheld and social media and often does not focus when invited to communicate.

Data collection technique in this studies is interview; observation; and documentation. Research Instruments in this study are a notebook to write about the interview in progress, it also can use the tape recorder to record what was discussed with the informant; checklist paper; and field note. After collecting the data and studying the information that is taken from some literary books that are closely related to this study, the researcher takes some steps to analyze the data. The following steps are done, as follows organizing, coding and reducing, interpreting and representing Ary (2010).

\section{FINDING AND DISCUSSION}

\section{Deaf Student and Deaf Students Communication \\ Verbal communication}

1) Oral

S1 did oral communication that sounded pretty obvious, but S1 more often speak in a low voice, even just lip movement. S2 uses unclear oral communications that are difficult to understand, while S3 uses unclear orally and is very difficult to understand

From the results of observations that researchers do get the conclusion that, when deaf student communicate with deaf children they use tend to be slow, fairly clear, not clear, very unclear or even no sound at all. When talking to S1 level, the oral used is slow but still clear and still sounds. For example when he says "saya nonton tv dirumah" his oral still sounds quite clear and can be understood almost in every word. When speaking with a medium level Deaf, the oral used is slow, vague and incomprehensible. For example when he speaks "diam saya ada sms" oral is not clear and sounds only on the word "diam" and even then it sounds like "hiyae and haaa". Meanwhile, when communicating with hearing-impaired people almost all words are very vague and no sound at all, more often communicating with language cues and eyes.

In S1 dean S2 environments more often use a combination of oral and body language communication while S3 more often use body language and facial expression, when they communicate with fellow deaf outside their school environment using SMS or chat, but when they communicate via text, the word that they made back and forth does not fit the rules.

When deaf communicate with each other, they tend to communicate using oral and sign language. They also use writing as their medium of communication at a certain time such as normal people communicating with normal people one example is SMS, but when they meet in person they will explain with sign language.

\section{Nonverbal communication}

1) Kinestict

a) Facial expression

From the results of observations that researchers do get the conclusion that, every time they always include facial expressions to clarify the message to be conveyed to the other person. As when he 
rejects something his expression will change, marked by both eyebrows meet and his mouth open. Or when the student feels happy, the front line is lifted up, both mouths will open and eyebrows lifted up. Or when the student was upset, the two eyebrows met, the mouth opened and slightly forward, when S1 said "aku tidak tahu" both eyebrows together and open mouth, this indicated he did not understand what the opponent to say. S2 "tidak, aku tidak mau" on the word "tidak" his expression turned annoyed this indicates he does not like.

b) Eyes contact

Eye contact and facial expression play an important role in conveying social messages and feelings; People accidentally often pay attention to other people's eyes to suspect the person's feelings. Through eye contact, one can also check whether the other person is paying attention to it and whether the other person agrees with the conversation. In some contexts, eye encounters often evoke strong feelings. In deaf hearing process communication, eye contact is very necessary to add information, when the deaf child loses eye focus then the information is not delivered, this is because hearing that is not functioning properly. Student 1 never loses eye focus on others or the object being discussed. While the student 2 more focused to the phone than others when invited to communicate. Student 3 is difficult to focus on others because more often bow.

c) Body posture and gesture

Sign language prioritizes manual communication, body language, and lip movement, rather than voice, to communicate. Deaf people are the main group that uses this language, usually by combining hand shape, orientation and gestures, arms, and body, and facial expressions to express their thoughts. Body posture and gesture is never released and always dominates every occurrence in the transfer of deaf children's information, such as shaking hands when they do not know, stretching their heads when facedown, pointing at the index finger when directing the spot. Shrug when not knowing. Open and closed lips movements, holding hands when inviting, turning the head, lifting both hands or clapping.

2) Haptict

Because their hearing is disturbed then one way to get their focus is to touch, such as slapping the shoulder or touching the hand. Each form has a purpose or feeling of the toucher. Touch can also cause a feeling to the recipient of touch, either positive or negative. When the focus that they have had to switch to the object or other place then the touch needed to restore focus on the opponent S2 often lose focus when invited to communicate, to get the focus back, should pat the shoulder or touch the hand S2. But different with S1, when S1 communicate with deaf student, he more focus on his partner of communicate.

3) Paralanguage

Knowing paralanguage communication of deaf students it is difficult to distinguish between oral communication and Paralanguage communication. Paralanguage always gives certain cues when deaf students communicate, paralanguage in deaf children occurs simultaneously with oral, when deaf student said "hahh hahh" it already includes paralanguage, for example when reject something and say "no" but sounds like "hahhh" accompanied by volume High will, or when he is 
interested to something and say "hahh hahh hahh" the volume is a little high and fast. Or "hahh hihya" in a low voice.

\section{4) Proxcemict}

In this study when deaf student communicate the other person's position should be at a close distance so as to facilitate the understanding of communication. Because verbal communication is not effective so it needs close communication such as mouth gesture or body gesture. For example, when deaf students are at a distance of less than 1-3 meters and they want to communicate then one of them must approach. For examples when deaf student trying to communicate with $\mathrm{S} 1$ and $\mathrm{S} 2$, they have to more close to get focus of S2.

\section{Deaf Students Communicate with Other Disability}

\section{Verbal communication}

\section{1) Oral}

From the observation that the researcher got data that when deaf children talk with oral down syndrome student who deaf students tend to slow, unclear, or even no sound at all, down syndrome student must repeat the sentence for students down syndrome, oral down syndrome sounds very Clearly while the oral deaf is slow and unclear.

Deaf students communicate with emphasis on hearing and lip and gesture movements. While down syndrome students do not use sign language or gesture to communicate. So when students with hearing impaired and Down syndrome students communicate there will be miscommunication on both levels. For example, when $\mathrm{S} 1$ asks a student's syndrome to call their teacher, the deaf student must repeat the phrase and the student down syndrome also takes a long time to understand what $\mathrm{S} 1$ says. Or when the student down syndrome asks $\mathrm{S} 2$ to get the glue, S2 also takes a long time to understand what is said by the student down syndrome.

\section{Nonverbal communication}

1) Kinestict

a) Facial expression

From the observations, when he rejects something his expression will change, marked with both eyebrows meet and his mouth open. Or when students feel happy, the front line is lifted, both mouths will open and eyebrows lifted. Or when the student is upset, the two eyebrows meet, the mouth is open and slightly forward, when S1 tells the student down syndrome to call bu Ninil, Down syndrome students do not understand what S1 said, so students Down syndrome repeating he said and show expression confused. Or when the student down syndrome asks the glue to $\mathrm{S} 2$ to extract glue, S2 does not seem to understand the words of Down syndrome students.

b) Eyes contact

Through eye contact, one can also check whether the other person is paying attention to it and whether the other person agrees with the conversation. In some contexts, eyes encounters often evoke strong feelings. In deaf hearing process communication, eye contact is very necessary to add information, when the deaf child loses eye focus then the information is not delivered, this is because hearing that is not functioning properly. Student 1 and student 2 never loses eye focus on others when communicate with down syndrome student. 
c) Body posture and Gesture

Posture and gestures are never released and always dominate every incident in the transfer of deaf children's information, such as shaking hands when they do not know, stretching their heads on their stomachs, pointing their index fingers while steering the spot. Know if you do not know. The movement of the lips is open and closed, holding hands while inviting, twisting, lifting both hands or clapping. S1 asked the student down syndrome to call bu Ninyil, he pointed down to hint the teacher office located on the first floor. Or S2 that lifts the glue to confirm whether the student requested Down syndrome or not.

2) Paralinguistic

The difference between deaf students and students with Down syndrome is one of them on oral. Oral deaf students tend to be unclear and difficult to understand while for their oral down syndrome students are still quite clear and easy to understand. Paralinguistic of syndrome student's more clear as when talking "emm" or intonation that go up according to what they say. Knowing the communication of deaf students' language is difficult to distinguish between oral communication and Paralanguage communication. When deaf students say "haah" it already includes paralanguage, for example when rejecting something and say "no" but sounds like "hahhh" accompanied by high volume of desire.

\section{Deaf Students and Normal People Verbal Communication}

a) Oral

When subject 1 communicates with the teacher, the oral still clear, there is still sound. But more often just lip movement while the teacher always uses the clear but slow mouth. With researchers, he uses oral that is not clear but still can be temporary researchers using oral clear, broken and slow. Subject 2, when talking to a teacher, he uses obscure and slow language while the teacher speaks verbally, inexplicably and has to repeat the sentence. With researchers, he used more sign language to use oral while the researchers used clear oral, slowly and slowly. Subject 3 when invited to communicate with the teacher he did not respond, more often silent and play mobile phones

b) Writing

When deaf students communicate with teachers, they do not use writing, because they understand sign language. The teacher uses a combination of oral and sign language, the oral spoken by the teacher is clear but slow so that the deaf student can follow the teacher's lips motion. While communicating with $\mathrm{S} 1$ and S2. Researchers use a combination of clear oral and body language because the researcher does not understand the sign language so students deaf initiative using stationery. So deaf student uses a combination of writing, body gesture and oral.

\section{Nonverbal Communication}

1) Kinestict

a) Facial expression

Deaf student, teacher, and researcher always include facial expressions to clarify the message to be delivered. Facial expression is more varied as when he rejects something his expression will change, marked with both eyebrows meet and his mouth open. Or when the student feels happy, the front line is lifted up, both mouths will open and eyebrows lifted up. Or when the student is upset, his eyebrows 
meet, the mouth is open and slightly forward to the fore.

b) Eyes contact

When communicating with a researcher or teacher. Student 1 never loses eye focus with the other person or the object being discussed. While student 2 is more focused on the phone than on the other person when invited to communicate, what if it has lost the focus of the eye then the communication will be disconnected, Student 3 difficult to focus on the other person, both teachers and researchers because more often.

In deaf hearing process communication, eye contact is very necessary to add information, when the deaf child loses eye focus then the information is not delivered, this is because hearing that is not functioning properly. Student 1 never loses eye focus on others or the object being discussed. While the student 2 more focused to the phone than others when invited to communicate. Student 3 is difficult to focus on others because more often bow.

c) Body posture and gesture

Body posture and gesture is never released and always dominates every occurrence in the transfer of deaf children's information, such as shaking hands when they do not know, stretching their heads when facedown, pointing at the index finger when directing the spot. Shrug when not knowing. Open and closed lips movements, holding hands when inviting, turning, lifting both hands or clapping.

2) Haptict

Because their hearing is disturbed then one way to get their focus is to touch, such as slapping the shoulder or touching the hand. Each form has a purpose or feeling of the toucher. Touch can also cause a feeling to the recipient of touch, either positive or negative. When the focus that they have had to switch to the object or other place then the touch needed to restore focus on the opponent S2 often lose focus when the teacher or researcher invited to communicate, to get the focus back, should pat the shoulder or touch the hand S2. But different with S1, when S1 communicate with teacher or researcher, he more focus on his partner to communicate.

3) Proxemic

Deaf students should take positions at close range to facilitate understanding of communication transfers. Because verbal communication is ineffective, requiring close communication such as oral gestures or body movements. When deaf students are at a distance less than 3 meters and they want to communicate then one should be approached. For example, when teacher or researcher tries to communicate with $\mathrm{S} 1$ and S2, the teacher or researcher should be closer to get focus from both and make it easier S1 and S2 to see body posture and gesture.

\section{CONCLUSION}

From the previous explanation and the research process can be concluded that in the communication types of deaf children, things that become obstacles in each individual are:

Deaf children's communication with deaf children is more dominant using nonverbal rather than verbal. They also use oral verbal communication. But the oral they use tends to be unclear even very unclear. Use of continuous verbal communication such as Kinestict (facial expression, eye contact, sign language), haptict, paralanguage, and proxemict.

Deaf children communication with other disability (down syndrome) is Deaf 
children's communication with dominant down syndrome children using nonverbal communication types. Down syndrome students are hard to understand oral used by deaf students. The use of intense verbal communication such as Kinestict (facial expressions, eye contact, sign language) and Haptict are two very important aspects of their communication.

Deaf children's communication with normal people use a combination of verbal (oral and writing) and nonverbal (kinestict, haptict, and proxemict). Teachers will use a clear combination of sign language and oral. While researchers use oral, written and sign language to make it easier for deaf students to understand the conversation.

\section{REFERENCES}

Afifudin \& Beni, Ahmad. (2009). Metodologi Penelitian Kualitatif. Bandung: CV Pustaka Setia.

Ary, Donald. (2010). Introduction to Research in Education (Eight edition). Wadsword Cencage Learning.

Burhan, Bungin. (2006). Sosiologi Komunikasi. Prenada media: Jakarta. Julia, Wood. (2009). Communication In Our Live (Fifth Edition). Cencage learning: Boston.

Kementerian kesehatan RI. (2014). Situasi Penyandang Disability. Bulletin jendela data. Jakarta.

Moores, D. F. (1974) in Language Perspectives (eds Schiefelbusch, R. L. \& Lloyd, L. L.) 377-878 University Park: Baltimore.

Somad \& Hermawati. (1995). Ortopedagogik Anak Tunarungu. Bandung.
Soemantri, Sutjihati. (2006). Psikologi Anak Luar Biasa. Bandung: Revika Aditama. 